\title{
Undifferentiated embryonic stem cells express ionotropic glutamate receptor mRNAs
}

\author{
Svenja Pachernegg ${ }^{1,2,3 \neq}$, Illah Joshi ${ }^{1,2,4 \ddagger}$, Elke Muth-Köhne ${ }^{1,2,3 \dagger}$, Steffen Pahl ${ }^{1,2,3}$, Yvonne Münster ${ }^{1}$, \\ Jan Terhag ${ }^{1,3,4}$, Michael Karus ${ }^{2,3,5 t}$, Markus Werner ${ }^{1+}$, Zhan-Lu Ma-Högemeier ${ }^{1,2}$, Christoph Körber ${ }^{1+}$, \\ Thomas Grunwald ${ }^{6+}$, Andreas Faissner ${ }^{5}$, Stefan Wiese ${ }^{7}$ and Michael Hollmann ${ }^{1 *}$ \\ 1 Department of Biochemistry I - Receptor Biochemistry, Ruhr University Bochum, Bochum, Germany \\ 2 International Graduate School of Neuroscience, Ruhr University Bochum, Bochum, Germany \\ ${ }^{3}$ Ruhr University Research School, Ruhr University Bochum, Bochum, Germany \\ ${ }^{4}$ DFG Graduate School 736, Ruhr University Bochum, Bochum, Germany \\ ${ }^{5}$ Department of Cell Morphology and Molecular Neurobiology, Ruhr University Bochum, Bochum, Germany \\ ${ }^{6}$ Department of Molecular and Medical Virology, Ruhr University Bochum, Bochum, Germany \\ 7 Group for Molecular Cell Biology, Department of Cell Morphology and Molecular Neurobiology, Ruhr University Bochum, Bochum, Germany
}

\section{Edited by:}

Dieter Wicher, Max Planck Institute for Chemical Ecology, Germany

\section{Reviewed by:}

Josef Bischofberger, University of

Basel, Switzerland

Katalin Schlett, Eötvös Lorand

University, Hungary

\section{${ }^{*}$ Correspondence:}

Michael Hollmann, Department of

Biochemistry I-Receptor

Biochemistry, Ruhr University

Bochum, Building NC, Level 6,

Room 170, Universitaetsstr. 150,

D-44780 Bochum, Germany

e-mail:michael.hollmann@

ruhr-uni-bochum.de

${ }^{\dagger}$ Present address:

Elke Muth-Köhne, Fraunhofer Institute for Molecular Biology and Applied Ecology, Aachen, Germany; Michael Karus, Institute of

Reconstructive Neurobiology,

University of Bonn, Bonn, Germany; Markus Werner, Department of Cell Physiology, Ruhr University Bochum, Bochum, Germany: Christoph Körber, Institute of Anatomy and Cell Biology,

Heidelberg University, Heidelberg, Germany

Thomas Grunwald, Fraunhofer Institute for Cell Therapy and Immunology, Leipzig, Germany

*These authors have contributed equally to this work.
Ionotropic glutamate receptors (iGluRs) do not only mediate the majority of excitatory neurotransmission in the vertebrate CNS, but also modulate pre- and postnatal neurogenesis. Most of the studies on the developmental role of iGluRs are performed on neural progenitors and neural stem cells (NSCs). We took a step back in our study by examining the role of iGluRs in the earliest possible cell type, embryonic stem cells (ESCs), by looking at the mRNA expression of the major iGluR subfamilies in undifferentiated mouse ESCs. For that, we used two distinct murine ES cell lines, 46C ESCs and J1 ESCs. Regarding 46C ESCs, we found transcripts of kainate receptors (KARs) (GluK2 to GluK5), AMPA receptors (AMPARs) (GluA1, GluA3, and GluA4), and NMDA receptors (NMDARs) (GluN1, and GluN2A to GluN2D). Analysis of 46C-derived cells of later developmental stages, namely neuroepithelial precursor cells (NEPs) and NSCs, revealed that the mRNA expression of KARs is significantly upregulated in NEPs and, subsequently, downregulated in NSCs. However, we could not detect any protein expression of any of the KAR subunits present on the mRNA level either in ESCs, NEPs, or NSCs. Regarding AMPARs and NMDARs, GluN2A is weakly expressed at the protein level only in NSCs. Matching our findings for iGluRs, all three cell types were found to weakly express pre- and postsynaptic markers of glutamatergic synapses only at the mRNA level. Finally, we performed patch-clamp recordings of 46C ESCs and could not detect any current upon iGluR agonist application. Similar to 46C ESCs, J1 ESCs express KARs (GluK2 to GluK5), AMPARs (GluA3), and NMDARs (GluN1, and GluN2A to GluN2D) at the mRNA level, but these transcripts are not translated into receptor proteins either. Thus, we conclude that ESCs do not contain functional iGluRs, although they do express an almost complete set of iGluR subunit mRNAs.

Keywords: ESCs, neuroepithelial cells, neural stem cells, synaptic markers, qRT-PCR, patch-clamp recordings

\section{INTRODUCTION}

Excitatory neurotransmission in the vertebrate CNS is mainly mediated by ionotropic glutamate receptors (iGluRs), which can be divided into three main subfamilies: NMDA receptors (NMDARs), AMPA receptors (AMPARs), and kainate receptors (KARs) (Hollmann and Heinemann, 1994). Besides their function in synaptic signal transduction, iGluRs are involved in neural development by modulating the proliferation, migration, and differentiation of neural progenitors both during embryonic and adult neurogenesis (Cameron et al., 1995; Haydar et al., 2000; Deisseroth et al., 2004; Luk and Sadikot, 2004; Manent et al., 2005). For instance, iGluR activation in embryonic neocortical slices has been reported to lead to reduced DNA synthesis (Loturco et al., 1995) as well as increased proliferation (Haydar et al., 2000). Furthermore, it has been shown that iGluR activation increases the proliferation of neural progenitor cells (Luk and Sadikot, 2004; Brazel et al., 2005). However, this effect in different brain regions is mediated by different subclasses of iGluRs. While AMPAR and KAR activation promotes proliferation in cortical progenitors, 
NMDAR activation increases proliferation of striatal progenitors (Luk and Sadikot, 2004).

Whereas the impact of iGluRs on the proliferation and differentiation of neural progenitor cells and neural stem cells (NSCs) has been studied extensively (Schlett, 2006), their expression and putative function in undifferentiated embryonic stem cells (ESCs) is far less well understood. So far, it has only been demonstrated that neuron-like cells derived from ESCs show kainateand NMDA-induced current responses (Bain et al., 1995; Finley et al., 1996; Kim et al., 2009), but the expression of potentially functional iGluRs in undifferentiated ESCs remained elusive.

Thus, we investigated the expression of functional iGluRs in undifferentiated ESCs by patch-clamp recordings and by iGluR expression analysis at the mRNA and protein levels in two distinct murine ESC lines. First, we used the well-defined ES cell line 46C, which expresses EGFP under the control of the Sox1 promoter (Ying et al., 2003; Conti et al., 2005; Muth-Kohne et al., 2010a,b). Since Sox1 is an early neuroectodermal marker, the generation of neuroepithelial precursor cells (NEPs) from 46C ESCs can easily be monitored via the expression of EGFP (Ying et al., 2003; Conti et al., 2005). NEPs can then be further differentiated into radial glia-like NSCs; and both NEPs and NSCs can be differentiated into neurons and glia, thus demonstrating their NSC character (Ying and Smith, 2003; Conti et al., 2005; Muth-Kohne et al., 2010a,b).

Regarding the expression of iGluRs in ESCs, we found subunits of all three major subfamilies of iGluRs to be expressed in ESCs at the mRNA but not at the protein level. Moreover, most of the iGluR subunits are not expressed at the protein level in 46C-derived NEPs or NSCs either. Additionally, we analyzed the expression patterns of pre- and postsynaptic markers in 46C ESCs, NEPs, and NSCs. Similar to our findings for iGluRs, all three cell types express glutamatergic synapse markers on the mRNA but not at the protein level. Lastly, patch-clamp recordings of 46C ESCs showed no current responses to direct AMPAR and KAR agonist application.

Additionally, we also checked the expression of iGluRs at the mRNA and protein levels in a different, independent ES cell line, namely J1 ESCs. We found transcripts of AMPAR, KAR, and NMDAR subunits to be expressed in undifferentiated J1 ESCs, but, similar to 46C ESCs, none of the investigated subunits was translated into receptor protein as confirmed by Western blotting.

Thus, we conclude the absence of functional iGluRs in undifferentiated ESCs.

\section{MATERIALS AND METHODS CELL CULTURE}

All cultured cells were maintained at $37^{\circ} \mathrm{C}$ and $5 \% \mathrm{CO}_{2}$. The genetically engineered 46C ESC line (kind gift of Dr. Austin Smith) obtained from E14Tg2a.IV mouse ESCs (Aubert et al., 2003; Ying et al., 2003) was grown in GMEM containing 10\% FCS, $10 \%$ tryptose phosphate, $0.1 \mathrm{mM}$ 2-mercaptoethanole, $1.8 \mathrm{mM}$ glutamine, and $1000 \mathrm{U} / \mathrm{ml}$ leukemia inhibitory factor (LIF) (Millipore). NEPs were differentiated from 46C ESCs in a neuroinductive medium as described previously (Ying and Smith, 2003). NSCs were generated from NEPs by the prolonged cultivation in N2B27 medium. The proliferative state of NSCs was maintained by adding EGF and FGF-2 (both $10 \mathrm{ng} / \mathrm{ml}$; Peprotech) to the N2B27 medium (Conti et al., 2005). J1 ESCs were grown in R1 medium (DMEM containing 20\% FCS, $0.05 \mathrm{mM}$ 2-mercaptoethanole, $2.0 \mathrm{mM}$ glutamine, $1 \mathrm{x}$ non-essential amino acids, and $1000 \mathrm{U} / \mathrm{ml} \mathrm{LIF})$.

\section{REVERSE TRANSCRIPTION AND QUANTITATIVE REAL TIME PCR}

Total RNA was isolated from tissue and cultured cells using the GeneElute Mammalian Total RNA Miniprep Kit (Sigma). Two microgram of total RNA of each sample were used for reverse transcription (SuperScript II Reverse Transcriptase; Invitrogen). For quantitative Real Time PCRs (qRT-PCRs), 50 ng cDNA per reaction was used as template. qRT-PCRs were performed on a Roche LightCycler (Roche) using the LightCycler Fast Start DNA Master Plus SYBR Green I Kit (Roche) according to the manufacturer's manual. The reaction was performed with an initial pre-incubation for $10 \mathrm{~min}$ at $95^{\circ} \mathrm{C}$, followed by 40 amplification cycles $\left(95^{\circ} \mathrm{C}\right.$ for $10 \mathrm{~s}, 59^{\circ} \mathrm{C}$ for $10 \mathrm{~s}$, and $72^{\circ} \mathrm{C}$ for $\left.20 \mathrm{~s}\right)$. A melting cycle was performed to determine melting temperatures of the amplified products $\left(95^{\circ} \mathrm{C}\right.$ for $0 \mathrm{~s}, 65^{\circ} \mathrm{C}$ for $15 \mathrm{~s}$, and melting by increasing the temperature to $95^{\circ} \mathrm{C}$ at a rate of $\left.0.1^{\circ} \mathrm{C} / \mathrm{s}\right)$. Whole brain RNA of neonatal (P3) C57BL/6 mice served as positive control. For primer sequences, see Table 1.

\section{IMMUNOCYTOCHEMISTRY}

After removal of the culture medium, adherent cells were briefly washed twice with PBS/A (PBS + 0.1\% (w/v) BSA). The cells were fixed with $4 \%(\mathrm{w} / \mathrm{v})$ PFA for $10 \mathrm{~min}$ at room temperature (RT) and incubated with the primary antibodies diluted in PBT1 (PBS $+1.0 \%(\mathrm{w} / \mathrm{v}) \mathrm{BSA}+0.1 \%(\mathrm{v} / \mathrm{v})$ Triton X-100) at RT for $30 \mathrm{~min}$. The following primary antibodies were used: anti-Oct4 (1:500; Santa Cruz Biotechnology), anti-nestin (1:500; rat401, Millipore), and anti-Pax6 (1:50; DSHB). After incubation with the primary antibody, the incubation with either Cy2- or Cy3-coupled speciesspecific secondary antibodies (1:500; Dianova) diluted in PBS/A was performed at RT for $30 \mathrm{~min}$. Finally, the cells were washed twice with PBS and mounted in PBS/glycerol (2:1). Pictures were taken at an Axioplan2 microscope with the AxioCam HRc camera using the AxioVision 4.4 and 4.5 software (Zeiss).

\section{WESTERN BLOTTING}

Total membrane fractions of tissues and cell cultures were obtained by hypotonic lysis (10 mM HEPES/KOH, $1.5 \mathrm{mM} \mathrm{KCl}$, $10 \mathrm{mM} \mathrm{MgCl}_{2}, 0.5 \mathrm{mM}$ DTT) followed by ultracentrifugation to pellet membrane-bound proteins $(100,000 \mathrm{~g} ; 1 \mathrm{~h})$. For SDSPAGE, $50 \mu \mathrm{g}$ of membrane proteins were loaded per sample. After transferring the proteins to nitrocellulose membranes, the membranes were reversibly stained with Ponceau S (0.2\% Ponceau S, 3\% trichloroacetic acid, 3\% sulfosalicylic acid) to check for the proper transfer of proteins in each lane. For immunoblot analysis, the following primary antibodies were used: anti-GluA1 (1:1000; kind gift of Dr. Richard Huganir), anti-GluA2 (1:500; BD Biosciences), anti-GluA2/3 (1:500; Millipore), anti-GluN1 (1:1000; kind gift of Dr. Nils Brose), anti-GluN2A (1:1000; Millipore), anti-GluN2B (1:500; BD Biosciences), anti-GluK2/3 (1:500; kind gift of Dr. Robert Wenthold), anti-GluK5 (1:500; Tocris), anti-synaptophysin (1:10,000; Novus Biologicals), 
Table 1 | List of primers used in the quantitative RT-PCRs.

\begin{tabular}{|c|c|}
\hline Gene & $\begin{array}{l}\text { Primer sequence (shown in } \\
5^{\prime} \rightarrow 3^{\prime} \text { ) }\end{array}$ \\
\hline GluA1 (s) & Gacaactcaagcgtccagaa \\
\hline GluA1 (as) & cgtcgctgacaatctcaagt \\
\hline GluA2 (s) & gaccagaacggaaaacgaat \\
\hline GluA2 (as) & ttcaagcccagatgtgtcat \\
\hline GluA3 (s) & cctcctgatcctcccaatg \\
\hline GluA3 (as) & cgctctctatgggggacacc \\
\hline GluA4 (s) & agaaggacccagtgaccaac \\
\hline GluA4 (as) & atgcagccagattagcagtg \\
\hline GluA4 (s) (3' end) & tgtagcgacgcccaaggg \\
\hline GluA4 (as) ( $3^{\prime}$ end) & gtacggccttggggcagt \\
\hline GluN1 (s) & gctgtacctgctggaccgct \\
\hline GluN1 (as) & gcagtgtaggaagccacgatgatc \\
\hline GluN2A (s) & gctacgggcagacagagaag \\
\hline GluN2A (as) & gtggttgtcatctggctcac \\
\hline GluN2A (s) ( $3^{\prime}$ end) & acagcaagaggagcaaatctc \\
\hline GluN2A (as) ( $3^{\prime}$ end) & tgtacacacgtctattgctgc \\
\hline GluN2B (s) & gctacaacacccacgagaagag \\
\hline GluN2B (as) & gagagggtccacactttcc \\
\hline GluN2C (s) & aaccacaccttcagcagcg \\
\hline GluN2C (as) & gacttcttgcccttggtgag \\
\hline GluN2D (s) & cgatggcgtctggaatgg \\
\hline GluN2D (as) & agatgaaaactgtgacggcg \\
\hline GluK1 (s) & gcccctctcaccatcacgtat \\
\hline GluK1 (as) & tggtcgatagagccttgggca \\
\hline GluK2 (s) & ttcctgaatcctctctccct \\
\hline GluK2 (as) & caccaaatgcctcccactatc \\
\hline GluK3 (s) & gggtgtcagctgtgtcctct \\
\hline GluK3 (as) & gacagagctttgggcatcagt \\
\hline GluK3 (s) (3' end) & atcgccattctgcagctaca \\
\hline GluK3 (as) (3' end) & ataggaggctggggcttgtg \\
\hline GluK4 (s) & caaaggcctgggaatggagaata \\
\hline GluK4 (as) & ccgccgcctgggatggata \\
\hline GluK5 (s) & cgacaccaagggctacggcat \\
\hline GluK5 (as) & ccgccacgaagacagcaatga \\
\hline synapsin-1 (s) & accctgggtgtttgcccagatg \\
\hline synapsin-1 (as) & acccacaacttgtacctgtcagacat \\
\hline synaptobrevin-2 (s) & ggtggatgaggtggtggacatc \\
\hline synaptobrevin-2 (as) & gctgaagtaaacgatgatgatgatgagg \\
\hline synaptophysin (s) & tggacgtggtgaatcagctggtg \\
\hline synaptophysin (as) & aaagtacacttggtgcagcctgaatg \\
\hline neuroligin-1 (s) & gatggaccagcgagaacattg \\
\hline neuroligin-1 (as) & atcgatcacaggtccaaagg \\
\hline PSD-95 (s) & ttgcagatcggagacaagat \\
\hline PSD-95 (as) & gatctcattgtccaggtgct \\
\hline$\beta$-actin (s) & cgttgacatccgtaaagacct \\
\hline$\beta$-actin (as) & caaagccatgccaatgttgtctct \\
\hline
\end{tabular}

$3^{\prime}$ end primers pick up the $3^{\prime}$ coding region of the corresponding gene (see also Figure 9). $s=$ sense; as = antisense.

anti-PSD-95 (1:250; BD Biosciences), and anti-calnexin (1:500; Santa Cruz Biotechnology). For detection, appropriate HRPconjugated secondary antibodies (1:10,000; Sigma) were used. Whole brain proteins of neonatal (P3) C57BL/6 mice served as positive control. For the removal of antibodies from previously probed Western blots to allow reprobing of the membranes with another antibody, the membranes were incubated for $2 \mathrm{~h}$ in stripping buffer (25 mM glycine; pH 2.0, 1\% SDS).

\section{PATCH-CLAMP RECORDINGS}

Whole-cell recordings from ESCs were performed at -60 to $-70 \mathrm{mV} 1$ day after plating, using an EPC-9 amplifier controlled by Pulse software (HEKA Elektronik). Currents were digitized at $10 \mathrm{kHz}$ and Bessel-filtered at $3 \mathrm{kHz}$. Pipettes were pulled from borosilicate glass to resistances of $4-5 \mathrm{M} \Omega$. The extracellular solution contained $140 \mathrm{mM} \mathrm{NaCl}, 4 \mathrm{mM} \mathrm{KCl}, 2 \mathrm{mM} \mathrm{CaCl}_{2}, 1 \mathrm{mM}$ $\mathrm{MgCl}_{2}$, and $10 \mathrm{mM}$ HEPES adjusted to $\mathrm{pH} 7.3$ with $\mathrm{NaOH}$. The pipette solution contained $130 \mathrm{mM}$ CsF, $2 \mathrm{mM} \mathrm{MgCl} 2,1 \mathrm{mM}$ $\mathrm{CaCl}_{2}, 11 \mathrm{mM}$ EGTA, and $10 \mathrm{mM}$ HEPES adjusted to $\mathrm{pH} 7.3$ with $\mathrm{KOH}$. Agonists (1-10 mM glutamate or $0.6-5 \mathrm{mM}$ kainate) were prepared in extracellular solution and rapidly applied using a theta capillary mounted onto a piezo-driven actuator (PI Physik Instrumente) as described previously (Korber et al., 2007).

\section{DATA ANALYSIS}

qRT-PCRs results were analyzed using Roche LightCycler Software 3.5. Quantitative real time data was obtained by mathematical modeling (Pfaffl, 2001). The expression of the genes of interest was normalized to the expression of the housekeeping gene $\beta$-actin ( $2^{\Delta \mathrm{Ct}}$ method). To additionally compare the expression of genes in the different stem cell types to their expression in a control, the data was also normalized to the expression of genes in mouse whole brain ( $2^{\Delta \Delta \mathrm{Ct}}$ method). Data are shown as mean \pm SE of the mean (s.e.m.). Statistics were calculated using Prism 5.0 software (GraphPad). To compare the expression of a given receptor subunit across various stem cell types, One-Way ANOVA followed by Tukey's multiple comparison post-hoc test was used. To compare the expression of a given receptor subunit across two different stem cell types, unpaired Student's $t$-test was used.

\section{RESULTS EMBRYONIC STEM CELLS EXPRESS iGluR mRNAs}

In this study, we used the well-studied genetically engineered ESC line 46C, which expresses EGFP under the control of the early neuroectodermal marker Sox1. Thus, the generation of Sox1-positive NEPs from ESCs can be monitored via the expression of EGFP (Ying et al., 2003; Conti et al., 2005). Upon prolonged cultivation in a neuroinductive medium, NEPs differentiate into radial glia-like NSCs. Previous studies investigated the expression of a diverse panel of embryonic and NSC markers at the mRNA and protein level in the 46C ESCs, NEPs, and NSCs (Ying et al., 2003; Conti et al., 2005; Muth-Kohne et al., 2010a,b). In this study, we initially confirmed the protein expression of a representative set of stem cell markers in the investigated cell types (Figure 1). Undifferentiated 46C ESCs express the ESC marker Oct4 (Figure 1A; red fluorescence). Via cultivation in a neuroinductive medium, ESCs differentiate into NEPs. 46C NEPs are Sox1-positive, as indicated by their green fluorescence (Figure 1B). Additionally, NEPs express the NSC marker nestin (Figure 1B; red fluorescence). After differentiation into NSCs, the expression of Sox 1 is downregulated and NSCs were 

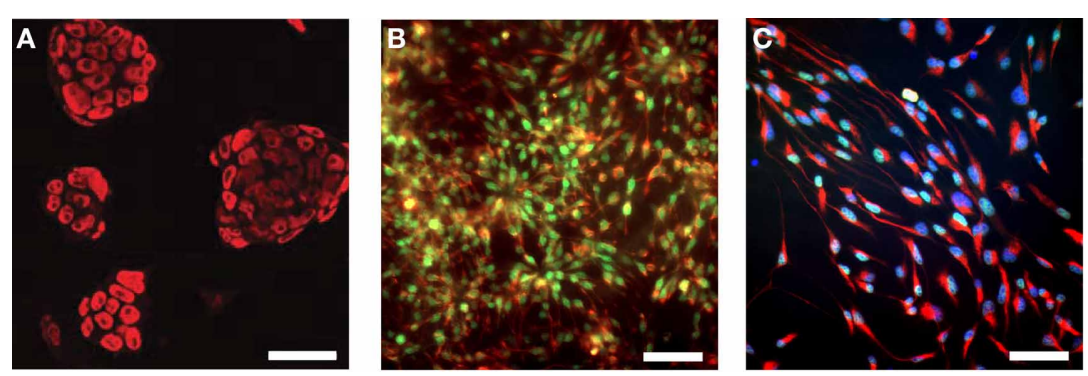

FIGURE 1 | Expression of embryonic and neural stem cell markers in 46C ESCs, NEPs, and NSCs. (A) ESCs express the embryonic stem cell marker Oct4 (red fluorescence). (B) NEPs express the neuroepithelial marker Sox1 (green fluorescence), as well as the neural stem cell marker nestin (red fluorescence). (C) NSCs express the neural stem cell markers Pax6 (green fluorescence) and nestin (red fluorescence). Here, nuclei were stained with Hoechst 33342 (blue fluorescence). Scale bars: $50 \mu \mathrm{m}$ (A) or $25 \mu \mathrm{m}(\mathbf{B}, \mathbf{C})$. shown to express the neural stem markers Pax6 (Figure 1C; green fluorescence) and nestin (Figure 1C; red fluorescence).

Next, we investigated the expression of iGluR mRNAs in undifferentiated 46C ESCs via qRT-PCR. Surprisingly, we found mRNA of all three subfamilies to be expressed in ESCs, albeit most of them were only weakly expressed and some subunits barely reached detection threshold (Figures 2-5). Among the probed iGluRs, two subunits are particularly highly expressed in $46 \mathrm{C}$ ESCs, namely the KAR subunit GluK3 and the NMDAR subunit GluN2A. Besides GluK3, 46C ESCs weakly express the KAR subunits GluK2, GluK4, and GluK5 (Figures 2, 3).

We also investigated the mRNA expression profile of KARs in cells of later developmental stages (46C NEPs and NSCs). In contrast to ESCs, NEPs and NSCs weakly express GluK1 (Figure 2). Regarding NEPs, the KAR subunits GluK2 to GluK5 are significantly upregulated in comparison to their expression in ESCs (Figures 2, 3). The strongest expressed KAR subunits in NEPs are GluK3 and GluK5 (Figure 2).

By comparing the expression of KAR subunits in NSCs to their expression in NEPs, we found all KAR subunits to be downregulated in NSCs (Figures 2, 3). In particular, the expression of GluK3 and GluK4 is significantly decreased in NSCs. Similar to NEPs, the KAR subunit GluK5 is strongly expressed in NSCs, as is GluK2. During the time course of development, we thus find an upregulation in the mRNA expression of GluK2 and GluK5, which are the major KAR subunits found at mature hippocampal mossy fiber synapses (Mulle et al., 1998; Contractor et al., 2003) and are generally regarded as the prevalent KAR heteromers in the adult brain (Lerma, 2003).

Regarding the mRNA expression of AMPAR subunits in 46C ESCs, the expression of GluA3 barely reached detection threshold and GluA1 is only weakly expressed (Figure 4). In contrast to that, 46C ESCs robustly express GluA4, since the expression of GluA4 in 46C ESCs accounts for 3\% compared to its expression in mouse whole brain (Figure 4B).

Moreover, NMDAR transcripts are expressed in 46C ESCs (Figure 5). In particular, we found a strong mRNA expression of GluN2A in undifferentiated 46C ESCs, which equals $~ 80 \%$ of its expression in mouse whole brain (Figure 5B). Previously, we already have analyzed NMDA and AMPA receptor expression at later developmental cell stages (Muth-Kohne et al., 2010a,b); whereas GluN2A remains the only robustly expressed NMDAR subunit also in 46C NEPs and NSCs, the AMPAR subunits GluA2, GluA3, and GluA4 are strongly upregulated in 46C NEPs and NSCs (Muth-Kohne et al., 2010a,b).

\section{EMBRYONIC STEM CELLS DO NOT EXPRESS FUNCTIONAL iGIUR PROTEIN COMPLEXES}

Based on the mRNA profiling results, we raised the question whether 46C ESCs not only express iGluR mRNAs, but also the corresponding protein complexes. Therefore, we performed Western blot analyses of plasma membrane proteins. As the strongest expressed iGluRs in 46C ESCs are the KAR subunits GluK3 and GluK5 (see Embryonic stem cells express iGluR mRNAs), we first investigated their protein expression in $46 \mathrm{C}$ ESCs. Both primary antibodies were specific, since they yielded a strong signal at the expected molecular weight $(\sim 120 \mathrm{kDa})$ in the positive control (plasma membrane proteins isolated from P3 mouse whole brain), but not in the negative control (plasma membrane proteins isolated from HEK293 cells) (Figure 6). However, we could not detect any GluK2/3 or GluK5 protein expression in 46C ESCs. Moreover, also cells of later developmental stages (NEPs and NSCs) do not express GluK2/3 or GluK5 at the protein level (Figure 6), although the mRNA expression of KAR subunits is strongly upregulated in NEPs (see Embryonic stem cells express iGluR mRNAs).

Similarly, neither the NMDAR subunits GluN1, GluN2A, or GluN2B nor the AMPAR subunits GluA1 or GluA2 are expressed at the protein level in 46C ESCs (Figure 7). By contrast, early neurons, which were differentiated from 46C NEPs via retinoic acid treatment, express both AMPAR and NMDAR proteins (Figure 7). Moreover, 46C NSCs weakly express GluN2A at the protein level, as we have shown previously (Muth-Kohne et al., 2010b).

Thus, undifferentiated 46C ESCs do express iGluR mRNAs, but they do not express iGluR proteins. To finally rule out the possibility of functional iGluR complexes in 46C ESCs, we performed whole-cell patch-clamp recordings of 46C ESCs. However, no current responses were detectable upon rapid direct application of either the endogenous agonist glutamate or the partial agonist kainate (Figure 8). This holds true both for low ( $1 \mathrm{mM}$ glutamate or $0.6 \mathrm{mM}$ kainate, Figure 8A) and high (10 $\mathrm{mM}$ glutamate or 

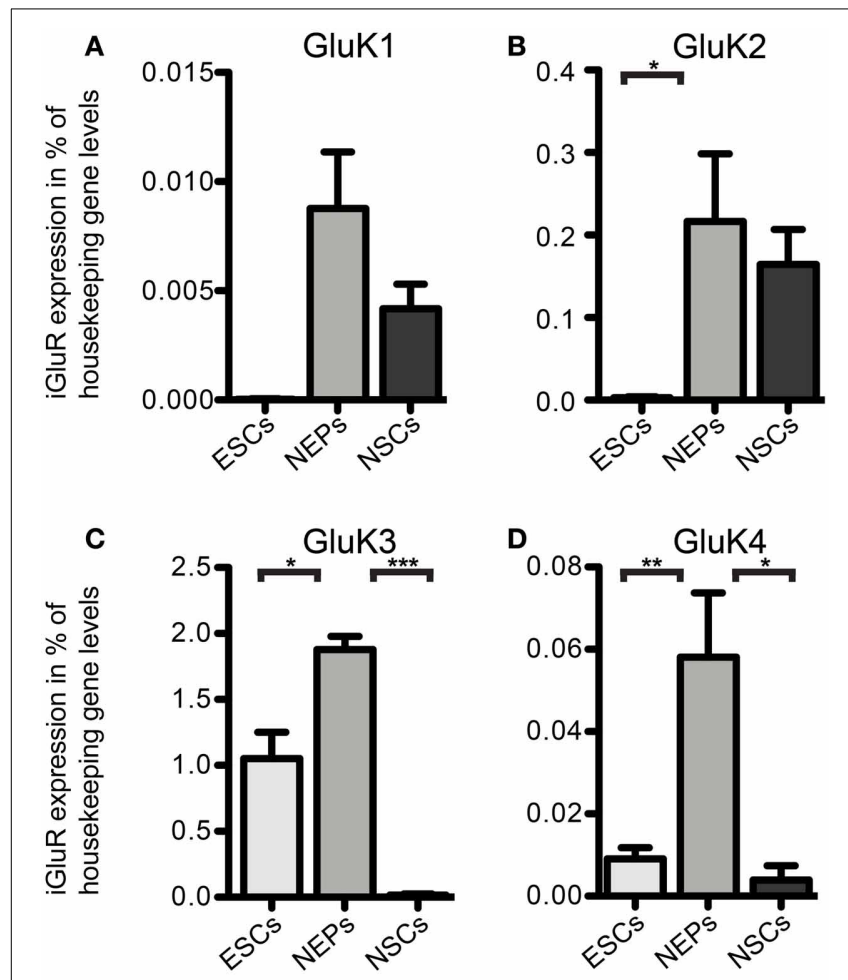

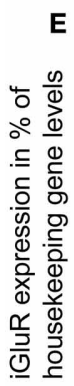

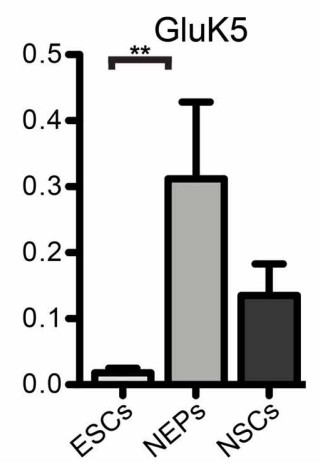

FIGURE 2 | Expression of KAR subunit mRNAs in 46C ESCs, NEPs, and NSCs normalized to the expression of the housekeeping gene $\beta$-actin $\left(\mathbf{2}^{\Delta \mathbf{C t}}\right)$. (A) GluK1. (B) GluK2. (C) GluK3. (D) GluK4. (E) GluK5. ESCs express KAR subunits at the RNA level; the most abundantly expressed KAR subunit in ESCs and NEPs is GluK3. The expression of all KAR subunits is upregulated upon differentiation into NEPs and subsequently downregulated in NSCs. Data represent mean \pm s.e.m.; statistical significances were assigned by One-Way ANOVA followed by Tukey's multiple comparison post-hoc test; ${ }^{*} p<0.05$; ${ }^{* *} p<0.01$; ${ }^{* * *} p<0.001$; $n=3-11$ independent experiments. Note that statistical differences in expression of receptor subunits were only calculated between ESCS/NEPs, and NEPS/NSCs, respectively, not between ESCs/NSCs, since ESCs cannot differentiate into NSCs without differentiating into NEPs first.

$5 \mathrm{mM}$ kainate, Figure 8B) agonist concentrations. These results clearly show that 46C ESCs do not express functional iGluR complexes at the plasma membrane.

To investigate whether 46C ESCs express full-length transcripts of iGluRs or whether only truncated transcripts are expressed, we used an additional, different set of primers for the highest expressed receptor subunits of each iGluR family in 46C

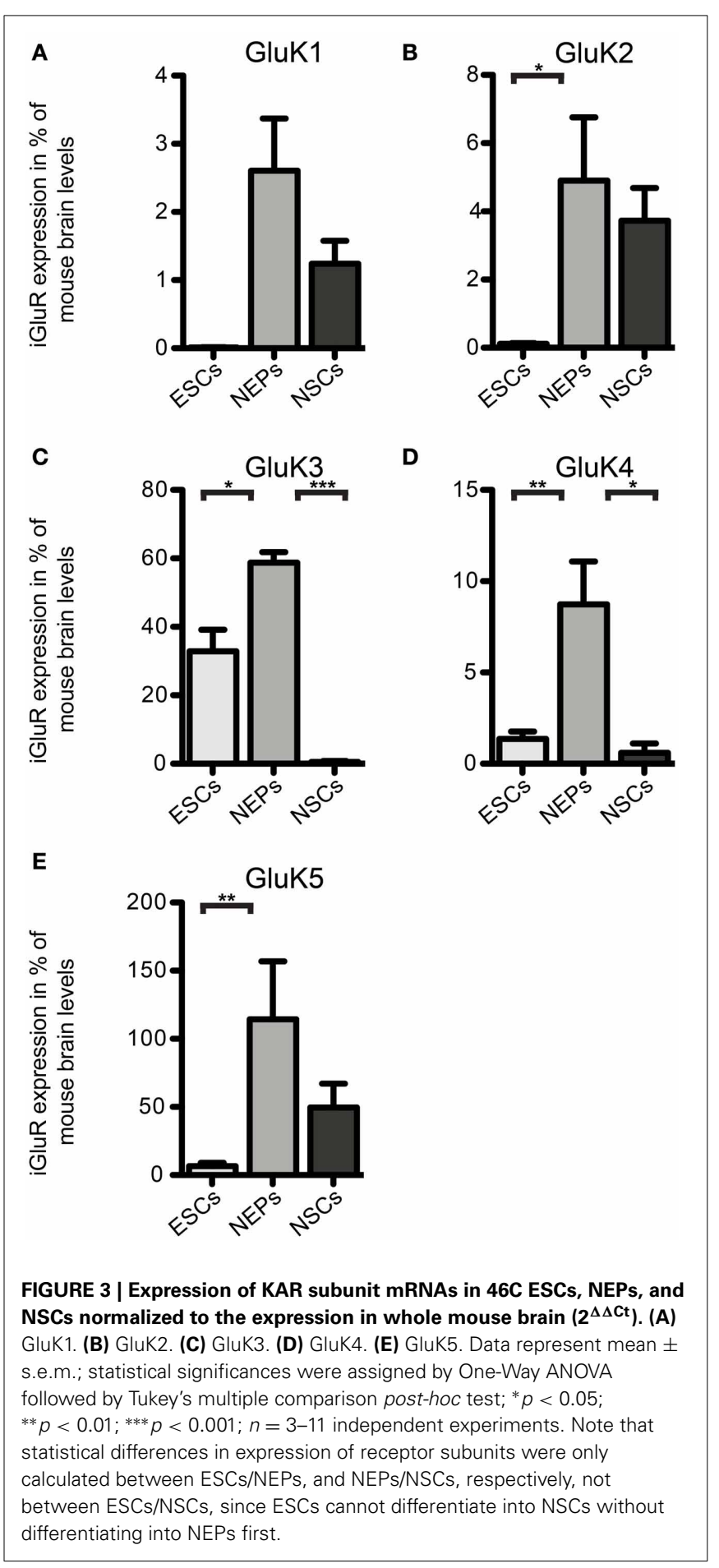

ESCs (namely GluA4, GluN2A, and GluK3). These primers pick up the $3^{\prime}$ coding region of the corresponding gene (Figure 9). Following qRT-PCRs, the amplified fragments were sequenced using an ABI 3130xl capillary sequencer (Applied Biosystems). GluA4, GluN2A, and GluK3 are indeed expressed as full-length transcripts in undifferentiated 46C ESCs, as confirmed by DNA sequencing.

Additionally, we checked the expression of iGluR transcripts in a different, non-engineered ESC line (J1 ESCs). We found 


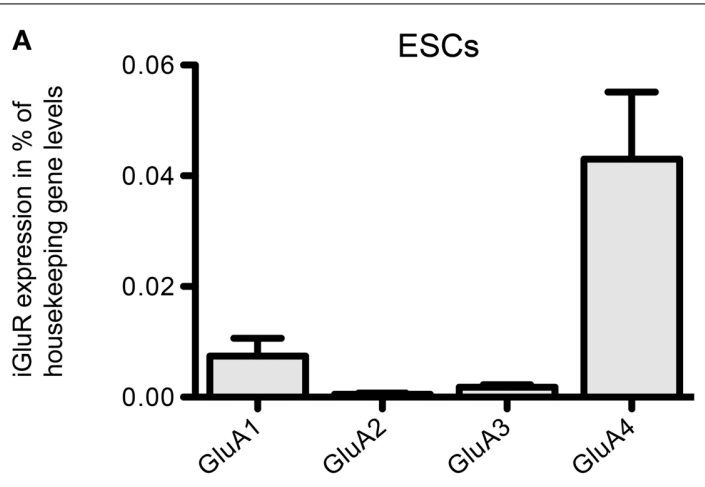

B

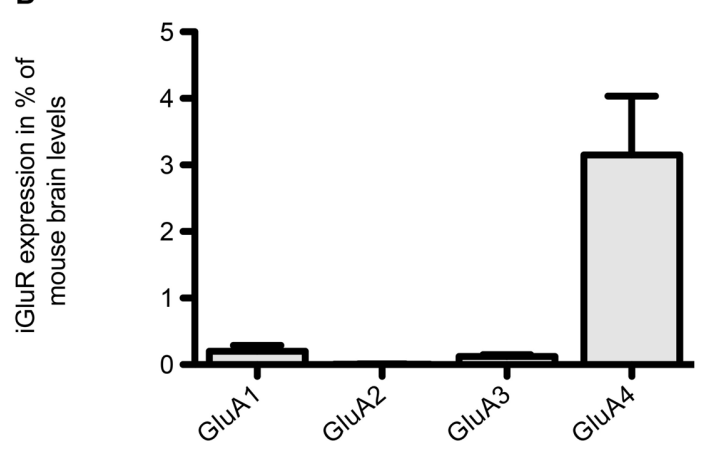

FIGURE 4 | Expression of AMPAR subunit mRNAs in 46C ESCs. (A) Expression normalized to the expression of the housekeeping gene $\beta$-actin $\left(2^{\Delta C t}\right)$. (B) Expression normalized to the expression in whole mouse brain $\left(2^{\Delta \Delta C t}\right)$. Whereas GluA2 is not expressed in ESCs, and GluA1 and GluA3 are only weakly expressed, ESCs robustly express the AMPAR subunit GluA4. Data represent mean \pm s.e.m.; $n=6-10$ independent experiments. Note that, here, no statistical differences were calculated, since we did not compare the expression of different receptor subunits within one cell type, but only across different cell types.

transcripts of all three iGluR families to be expressed in undifferentiated J1 ESCs (Figure 10), albeit their expression does not exactly match the expression of receptor subunits in undifferentiated $46 \mathrm{C}$ ESCs.

The only expressed AMPAR subunit in J1 ESCs is GluA3, which is only weakly expressed in these cells. GluA1, GluA2, and GluA4 are not expressed in J1 ESCs (Figure 10A). In contrast to that, 46C ESCs do not only express GluA3, but also GluA1 and, most prominently, GluA4 (Figures 4, 10A). Regarding NMDAR subunits, J1 express all NMDAR subunits at the RNA level (Figure 10B). In comparison to 46C ESCs, the expression of GluN1 and GluN2C is significantly higher in J1 ESCs than in 46C ESCs. Conversely, GluN2A is significantly lower expressed in J1 ESCs than in 46C ESCs. The mRNA expression of KARs in J1 ESCs is similar to their expression in 46C ESCs: GluK1 is neither expressed in J1 ESCs nor in 46C ESCs, and GluK2, GluK4, and GluK5 are only weakly expressed at the RNA level in both ESC lines. GluK3 is the highest expressed KAR subunit in both J1 and 46C ESCs, and its expression does not differ significantly between both ESC types (Figure 10C).

Next, we investigated whether iGluR subunits are expressed at the protein level in undifferentiated J1 ESCs. Therefore, we
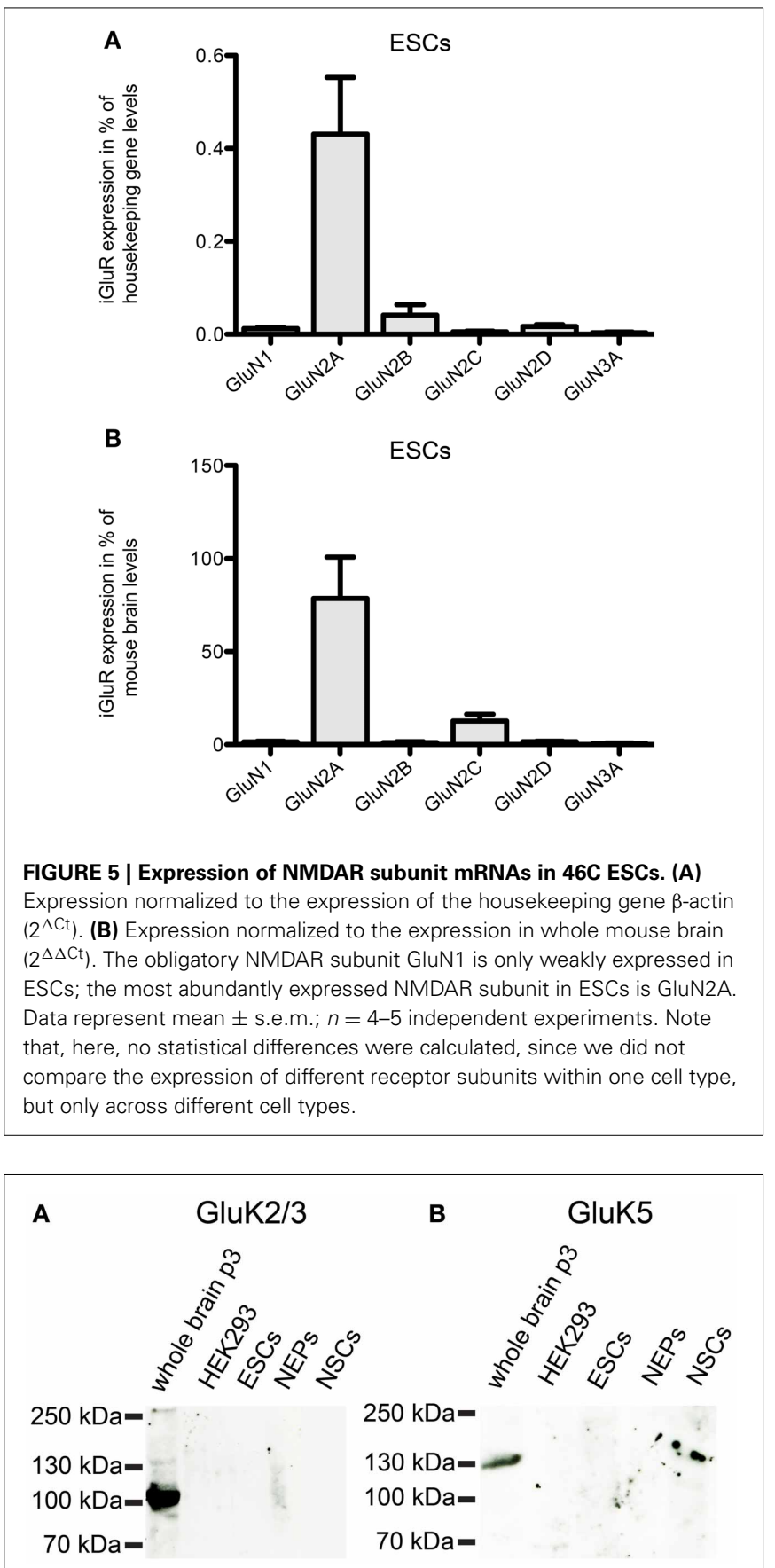

FIGURE 6 | Expression of KAR subunit proteins in 46C ESCs, NEPS, and NSCs. Protein isolated from neonatal whole mouse brain (P3) was used as a positive control; protein from HEK293 cells served as negative control. (A) GluK2/3. (B) GluK5. A band at the expected molecular weight of the receptor subunits ( $115 \mathrm{kDa}$ for GluK2/3 and $120 \mathrm{kDa}$ for GluK5) is only visible in the positive control. Neither ESCs nor NEPs or NSCs express GluK2/3 or GluK5 at the protein level.

performed Western blots with plasma membrane proteins isolated from J1 ESCs and used antibodies directed against GluN1, GluA2/3, and GluK2/3 to probe these blots. J1 ESCs do not express any of the investigated iGluR subunits at the protein 


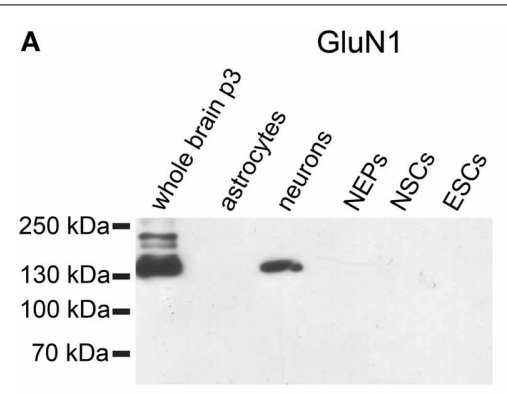

D

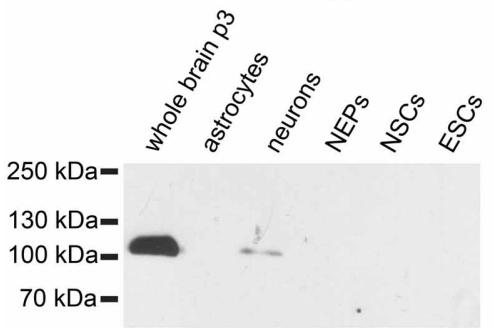

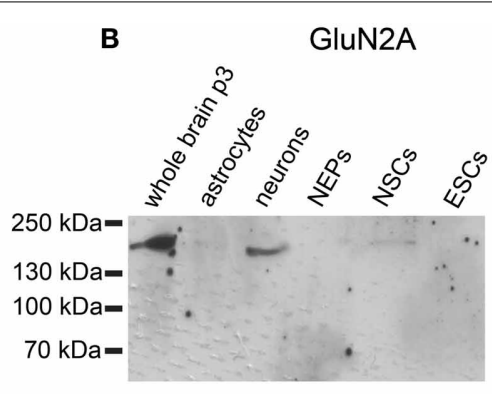

E

GluA2

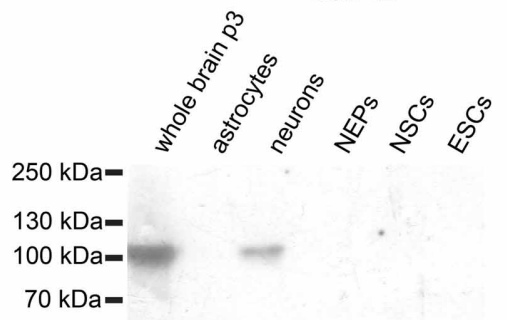

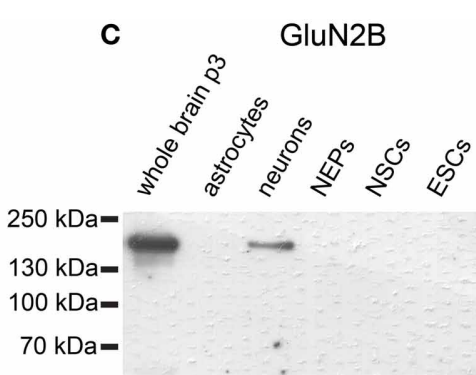

$\mathbf{F}$

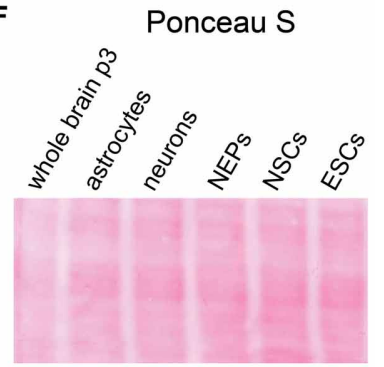

FIGURE 7 | Expression of AMPAR and NMDAR subunit proteins in 46C ESCs, NEPs, and NSCs. Protein isolated from neonatal whole mouse brain (P3) was used as a positive control. Additionally, protein from early neurons and astrocytes was applied. (A) GluN1. (B) GluN2A. (C) GluN2B. (D) GluA1. (E) GluA2. All antibodies yielded a band at the expected molecular weight (130 kDa for GluN1, $170 \mathrm{kDa}$ for GluN2A and GluN2B, $105 \mathrm{kDa}$ for GluA1, and $100 \mathrm{kDa}$ for GluA2) in the positive control. ESCs do not express any of the investigated NMDAR or AMPAR subunit proteins. (F) Exemplary Ponceau $S$ staining of proteins blotted on a nitrocellulose membrane.

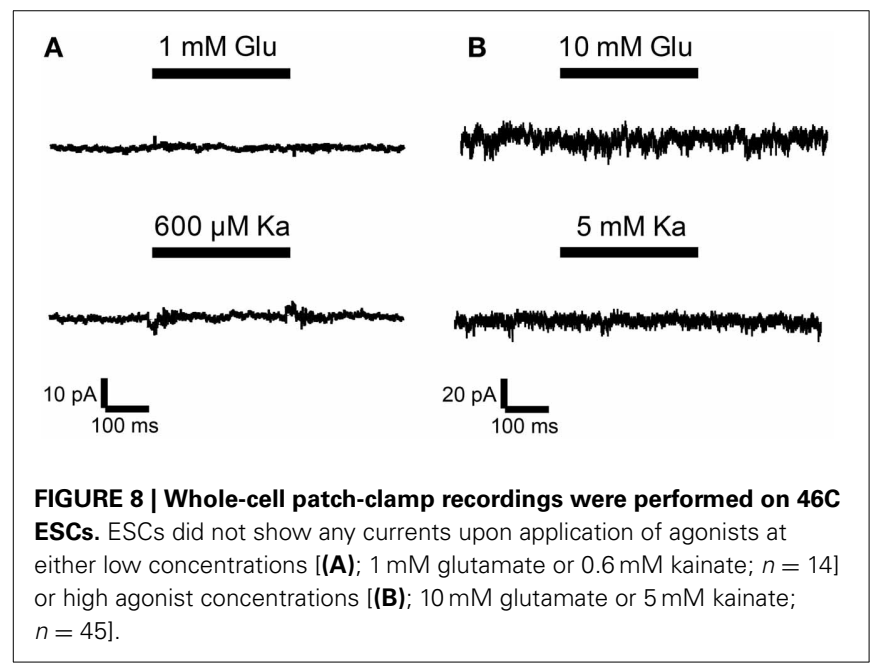

level (Figure 11), confirming that lack of receptor protein expression in 46C ESCs (Figures 6, 7) in presence of respective mRNA expression is not a unique property of 46C ESCs.

\section{STEM CELLS EXPRESS GLUTAMATERGIC SYNAPSE MARKER mRNAs, BUT NOT THE CORRESPONDING PROTEINS}

After establishing the expression of iGluR mRNAs but failing to detect any corresponding plasma membrane-resident protein complexes, we investigated whether 46C ESCs, NEPs, and NSCs also express the mRNAs of other proteins present at typical glutamatergic synapses. Therefore, we determined the mRNA expression of the presynaptically expressed synaptic vesicle proteins synapsin-1, synaptobrevin-2, and synaptophysin, as well as of the postsynaptic markers neuroligin-1 and PSD-95.

46C ESCs robustly express mRNAs of the presynaptic marker synapsin-1, whereas synaptobrevin-2, synaptophysin, and PSD95 are only weakly expressed (Figure 12). mRNA for the postsynaptic marker neuroligin-1 could not be detected at all in ESCs. During the development from ESCs to NEPs and, subsequently, to NSCs, all synaptic marker mRNAs are upregulated. However, while the mRNA levels of synapsin-1 and synaptophysin are comparable between 46C NEPs and NSCs, the mRNAs of synaptobrevin-2, neuroligin-1, and PSD-95 are upregulated in NSCs (Figure 12), although this upregulation is not statistically significant. However, as for the iGluR subunits, we were unable to confirm the presence of the presynaptic marker synaptophysin or of the postsynaptic marker PSD-95 at the protein level in 46C ESCs (Figure 13). A band at the expected molecular weight (38 kDa for synaptophysin and $95 \mathrm{kDa}$ for PSD-95) is only visible in early neurons differentiated from 46C NEPs or in membrane proteins isolated from whole mouse brain (Figure 13). Regarding PSD-95, there is an additional band visible $(\sim 60 \mathrm{kDa})$ in early neurons, and a very faint crossreactive band in NEPs, which might depict a cross-reacting protein. However, in NEPs, no band is visible at the expected molecular weight of PSD-95.

\section{DISCUSSION}

\section{UNDIFFERENTIATED EMBRYONIC STEM CELLS EXPRESS iGIuR TRANSCRIPTS}

In the present study, we analyzed the expression of KARs, AMPARs, and NMDARs in 46C and J1 ESCs as well as the 


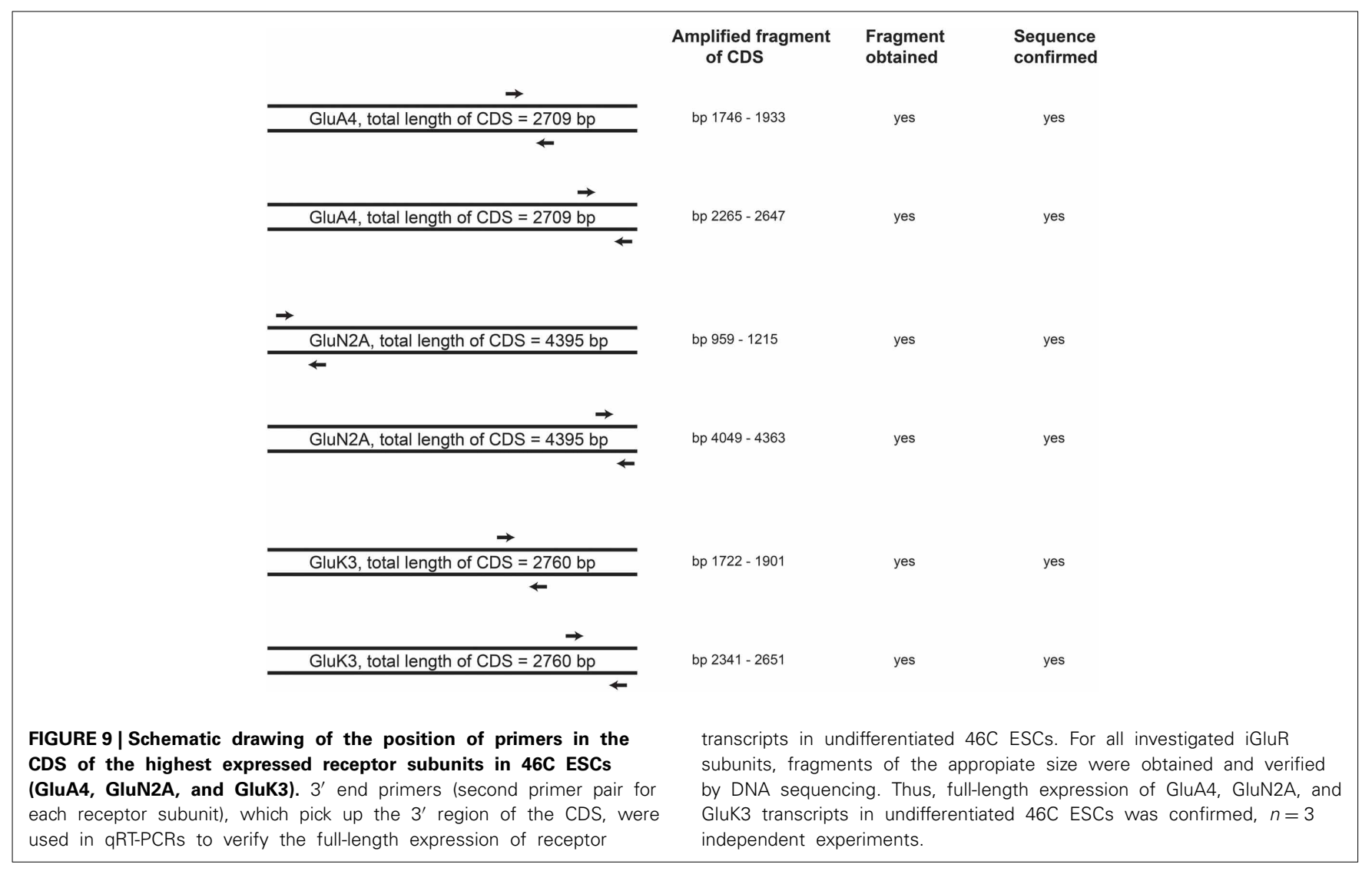

expression of KARs in 46C-derived NEPs and NSCs. Surprisingly, we found subunits of all three iGluR families to be expressed at the mRNA level in both ESC lines, although we could not detect any iGluR protein expression. Additionally, we ruled out the possibility of functional iGluRs in undifferentiated 46C ESCs, as whole-cell patch-clamp recordings gave no currents upon glutamate or kainate application. We also investigated the expression of several glutamatergic synapse marker mRNAs in 46C ESCs, NEPs, and NSCs, and found that all three cell types express both pre- and postsynaptic markers at the RNA level. However, similar to our findings regarding iGluR expression, the mRNA expression of synaptic markers in stem cells does not result in protein expression.

Recent studies indicate that a promiscuous transcriptional activity, which does not necessarily result in protein translation, might be a general principle of undifferentiated ESCs (Sperger et al., 2003; Golan-Mashiach et al., 2005; Meshorer and Misteli, 2006; Efroni et al., 2008). This holds also true for lineage- and tissue-specific genes (Efroni et al., 2008). The unique structure of chromatin in ESCs might be the reason for their global transcriptional activity, since their chromatin is generally maintained in an open conformation (Meshorer and Misteli, 2006). Furthermore, the chromatin of ESCs shows a looser binding of architectural proteins (Meshorer and Misteli, 2006). Taken together, these features of ESCs might explain the mRNA expression of iGluRs and glutamatergic synapse markers, although their transcription does not lead to protein translation.
So far, only few studies analyzed the expression of KARs during rodent brain development, in which the mRNA of KAR subunits was detected as early as E10 in rat embryos (Bahn et al., 1994; Scherer and Gallo, 1998; Lilliu et al., 2002; Ritter et al., 2002). We now raised the question whether KAR transcripts are expressed in undifferentiated ESCs as well and found that mRNAs for all KAR subunits except for GluK1 are expressed in undifferentiated 46C and J1 ESCs, with GluK3 mRNA being the most abundant. After differentiation from 46C ESCs to NEPs, the expression of all KAR mRNAs is significantly increased and, subsequently, decreased when NEPs are differentiated into NSCs (Figures 2, 3).

To further investigate the expression of KAR subunits in $46 \mathrm{C}$ ESCs, NEPs, and NSCs, we performed Western blot analyses with GluK2/3 and GluK5 antibodies. We found that neither GluK2, GluK3, nor GluK5, are expressed at the protein level in any of the analyzed cell types (Figure 6). Additionally, undifferentiated J1 ESCs do not express GluK2 or GluK3 subunits at the protein level either (Figure 11).

Besides the expression of KARs, we also investigated the expression of AMPARs and NMDARs in undifferentiated ESCs. Mirroring our findings for KAR expression in ESCs, 46C and J1 ESCs express AMPAR and NMDAR subunits at the RNA level, but these transcripts are not translated into receptor proteins.

Regarding AMPARs, it has been shown that their expression starts early during development (Monyer et al., 1991; Jansson et al., 2011). We now found that undifferentiated 46C ESCs also express GluA1 and GluA4 transcripts (Figure 4), and that in cells 

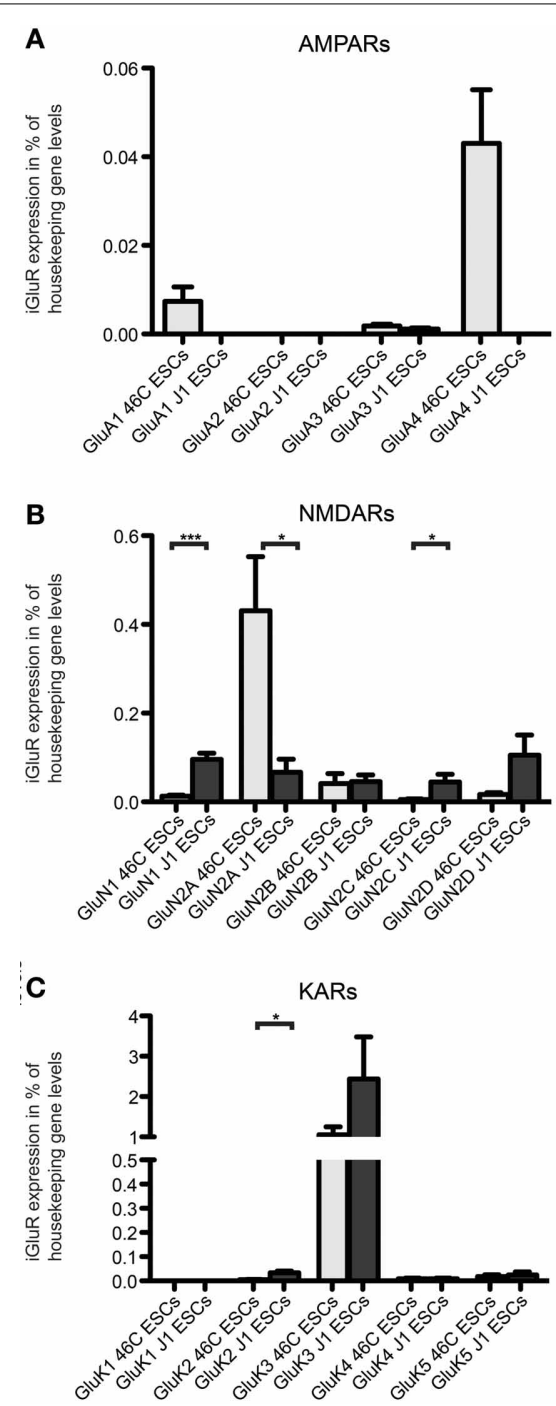

FIGURE 10 | Expression of AMPAR (A), NMDAR (B), and KAR (C) mRNAs in 46C ESCs and J1 ESCs normalized to the expression of the housekeeping gene $\boldsymbol{\beta}$-actin $\left(\mathbf{2}^{\mathbf{\Delta} \mathbf{C t}}\right)$. Undifferentiated J1 ESCs express iGluR subunits at the RNA level. The only expressed AMPAR subunit in J1 ESCs is GluA3, which is only weakly expressed. In contrast to that, J1 ESCs express transcripts of all NMDAR subunits, and the expression of GluN1 and GluN2C is significantly higher in J1 ESCs than in 46C ESCs. The strongest expressed KAR transcript in both 46C ESCs and J1 ESCs is GluK3. Data represent mean \pm s.e.m.; statistical significances were assigned by unpaired Student's $t$-test; ${ }^{*} p<0.05$; ${ }^{* * *} p<0.001 ; n=3-11$ independent experiments.

of later developmental stages (i.e., NEPs and NSCs) the expression of GluA2-GluA4 is upregulated (Muth-Kohne et al., 2010a,b).

Interestingly, 46C ESCs robustly express GluA4 mRNA. In contrast to that, the only expressed AMPAR subunit in undifferentiated J1 ESCs is GluA3. Thus, GluA4 is not expressed at all in J1 ESCs. This difference in AMPAR expression at the RNA level in 46C and J1 ESCs might be due to the fact that 46C and J1 cells are different ES cell lines of different origin with a different culturing history.

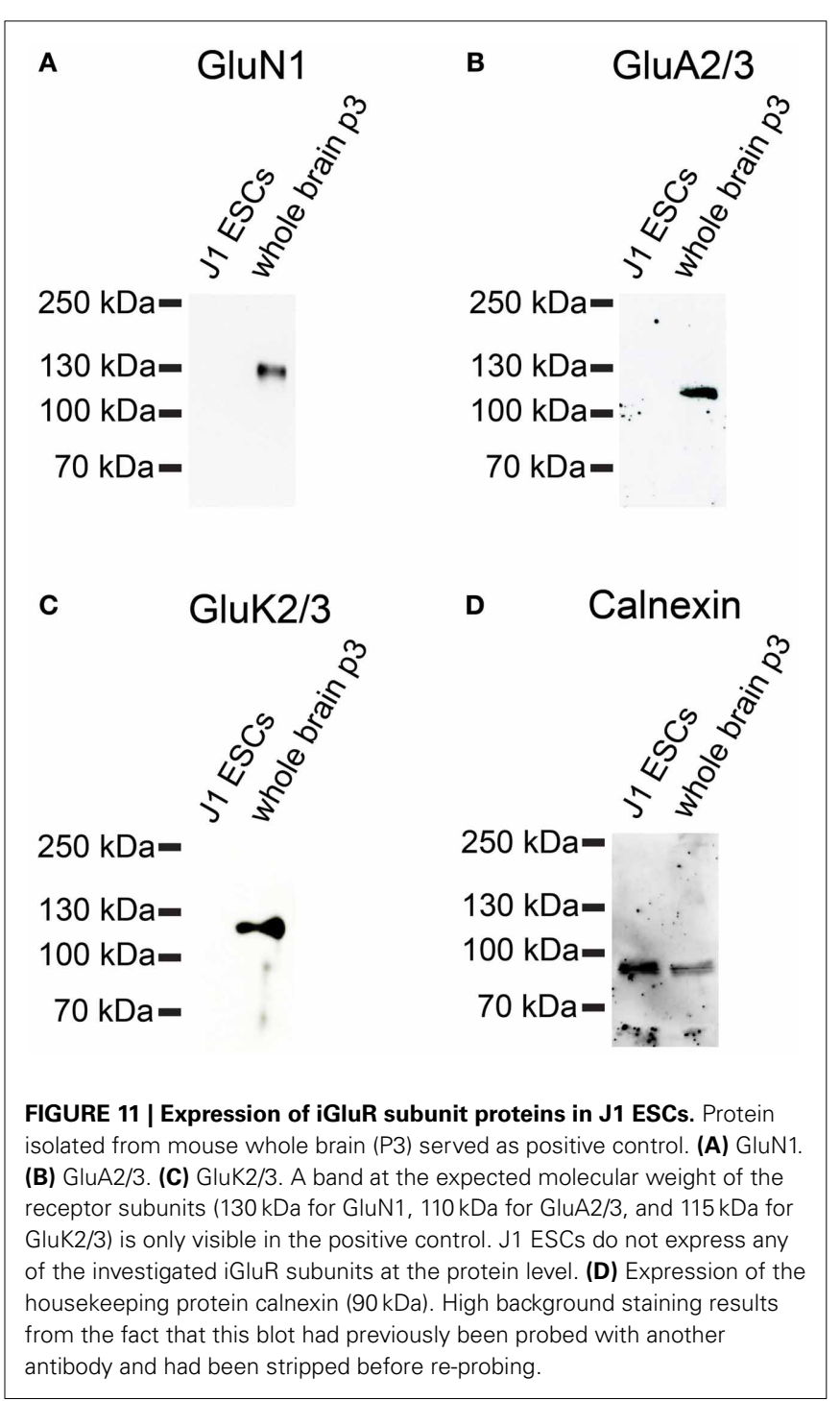

Nevertheless, we could not detect any AMPAR protein expression neither in 46C ESCs, NEPs, or NSCs, nor in J1 ESCs (Figures 7, 11).

Similar to AMPARs and KARs, NMDARs are present early during neural development (Monyer et al., 1994; Liu et al., 2004). We found that although undifferentiated 46C ESCs express also GluN2B transcripts, the most strongly expressed NMDAR subunit at the mRNA level in 46C ESCs is GluN2A (Figure 5). Nevertheless, we found weak protein expression of GluN2A only in 46C NSCs (Figure 7) (Muth-Kohne et al., 2010b). However, the obligatory NMDAR subunit GluN1 is not present at the protein level, neither in 46C ESCs, NEPs, nor NSCs, although it is expressed at the mRNA level (Figures 5, 7) (Muth-Kohne et al., 2010a,b). Thus, functional NMDARs cannot assemble in any of these three cell types. Similar to that, undifferentiated J1 ESCs express transcripts of all NMDAR subunits (Figure 10), and the expression of GluN1 is even significantly higher in J1 ESCs than in 46 ESCs. Nevertheless, GluN1 is not expressed at the protein level in J1 ESCs either (Figure 11). 

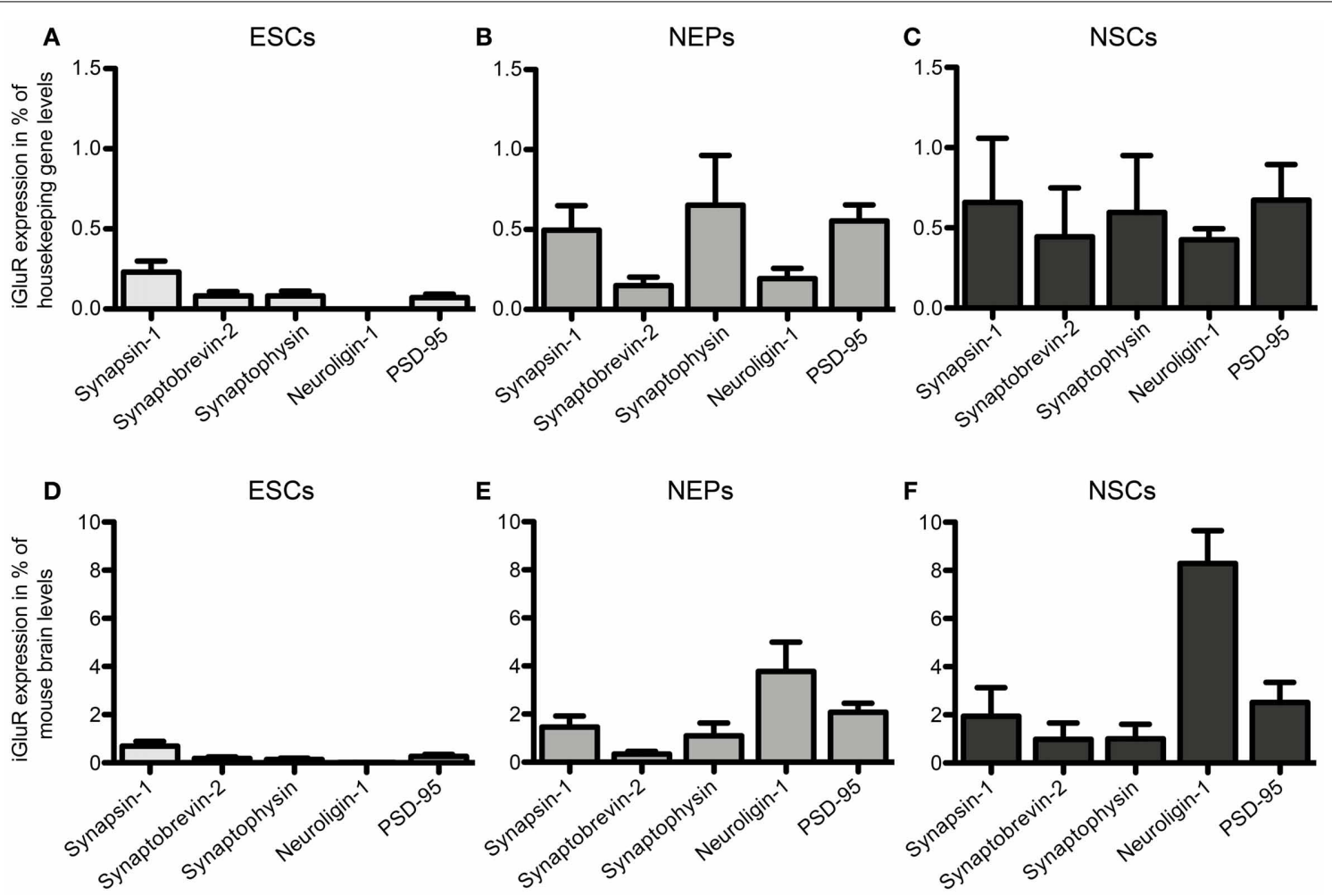

FIGURE 12 | Expression of presynaptic (synapsin-1, synaptobrevin-2, synaptophysin) and postsynaptic (neuroligin-1 and PSD-95) marker mRNAs in 46C ESCs, NEPs, and NSCs normalized to the expression of the housekeeping gene $\beta$-actin $(A-C)\left(2^{\Delta C t}\right)$ and the expression in whole mouse brain (D-F) $\left(2^{\Delta \Delta C t}\right)$. (A,D) Expression in ESCs. (B,E) Expression in NEPs. (C,F) Expression in NSCs. ESCs weakly express pre- and postsynaptic markers at the mRNA level. The expression of synaptic markers is then continuously upregulated upon

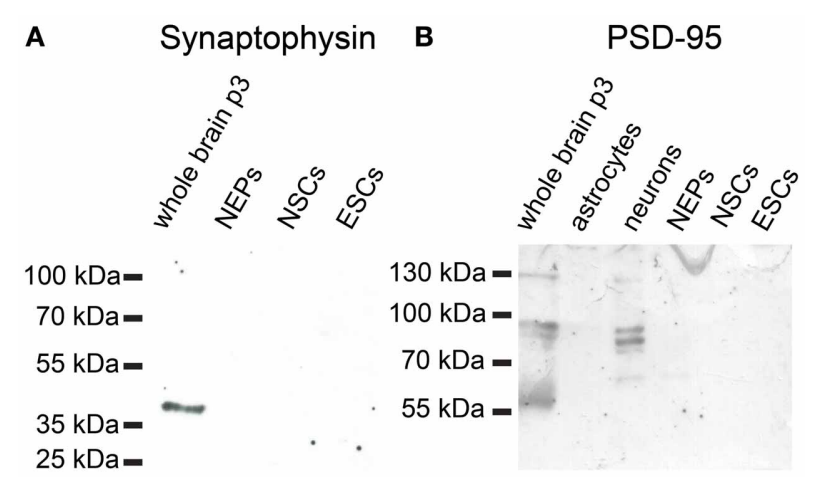

FIGURE 13 | Expression of synaptic marker proteins in 46C ESCs, NEPs, and NSCs. Protein isolated from early neurons and/or neonatal whole mouse brain (P3) was used as a positive control. (A) Synaptophysin (38 kDa). (B) PSD-95 (95 kDa). Neither type of stem cell expresses synaptophysin or PSD-95 proteins.

Additionally, we confirmed the presence of full-length transcripts of the strongest expressed receptor subunits (namely GluA4, GluN2A, and GluK3) in undifferentiated 46C ESCs (Figure 9). Thus, full-length transcripts of iGluRs are present differentiation into NEPS and NSCs. Data represent mean \pm s.e.m.; $n=5-6$ independent experiments. Note that statistical differences in the expression of markers were only calculated between ESCS/NEPs, and NEPs/NSCs, respectively, not between ESCs/NSCs, since ESCs cannot differentiate into NSCs without differentiating into NEPs first. Between ESCs/NEPs and NEPs/NSCs, no significant differences were found by One-Way ANOVA followed by Tukey's multiple comparison post-hoc test. in undifferentiated 46C ESCs, but they are not translated into receptor proteins.

\section{UNDIFFERENTIATED EMBRYONIC STEM CELLS DO NOT FORM FUNCTIONAL iGluRs}

In addition to the analysis of iGluR mRNA expression patterns, we also investigated the expression of pre- and postsynaptic markers in 46C ESCs, NEPs, and NSCs. In general, the mRNA expression of all synaptic markers examined in this study is slightly upregulated during differentiation from ESCs to NEPs and NSCs (Figure 12).

However, synaptophysin is not expressed at the protein level, neither in 46C ESCs, NEPs, nor NSCs (Figure 13). Similar to that, the staining of synapsin-1 and synaptophysin proteins is restricted to cells with neuronal morphology when ESCs are differentiated into neuronal cells by treatment with retinoic acid (Finley et al., 1996).

Regarding the postsynaptic marker PSD-95, we could not detect its protein expression in any of the investigated stem cell types (Figure 13), but only in whole mouse brain and neurons differentiated from 46C NEPs. Nevertheless, there is a very faint crossreactive band visible in NEPs at a lower molecular weight $(\sim 60 \mathrm{kDa})$ than the expected molecular weight of 
PSD-95 (95 kDa). This might depict an unrelated cross-reacting protein.

Among the presynaptic markers investigated in this study, synapsin-1 is robustly expressed at the mRNA level in undifferentiated 46C ESCs, as well as in NEPs and NSCs. Synapsin-1 has been shown to be expressed early (E12-14) during development and to play a key role in the maturation of glutamatergic synapses and in the biogenesis of synaptic vesicles (Melloni and Degennaro, 1994; Zurmohle et al., 1994; Bogen et al., 2009; Vasileva et al., 2012).

Thus, similar to the expression of iGluR transcripts, which are not translated into receptor proteins, undifferentiated ESCs do express pre- and postsynaptic markers at the mRNA level, but not at the protein level.

It has been demonstrated that neurons derived from ESCs via treatment with retinoic acid show currents in response to the application of NMDA or kainate (Bain et al., 1995; Finley et al., 1996; Kim et al., 2009). In the present study, we raised the question whether undifferentiated ESCs could express functional iGluRs as well. First, we observed robust mRNA expression of the KAR subunits GluK3 and GluK5 as well as the AMPAR subunit GluA4 and the NMDAR subunit GluN2A in undifferentiated 46C ESCs. However, we could not detect any protein expression of iGluRs in ESCs. To rule out the possibility of an insufficient sensitivity of the protein detection method, we performed patchclamp recordings of 46C ESCs. Undifferentiated 46C ESCs did not show any current responses when glutamate or kainate were applied to the cells (Figure 8). This is in line with the observed lack of receptor proteins in undifferentiated ESCs. Similar to our results, Maric et al. (2000) showed that neural precursors from E13 rat neuroepithelium express iGluRs at the mRNA level, while glutamate-activated currents could only be observed in differentiating neurons, not in proliferating neural precursors (Maric et al., 2000).

In summary, undifferentiated $46 \mathrm{C}$ and J1 ESCs were shown to express subunits of all three major subfamilies of iGluRs (KARs, AMPARs, and NMDARs) at the mRNA level. Similar to that, preand postsynaptic marker mRNAs were present in 46C ESCs and in cells of later developmental stages, namely NEPs and NSCs. However, with the exception of GluN2A in NSCs, none of these transcripts could be detected at the protein level. Additionally, the expression of functional iGluRs in 46C ESCs was ruled out since patch-clamp recordings of 46C ESCs gave no currents upon iGluR agonist application. It has been postulated before that ESCs globally express a wide variety of genes, including lineage- and tissue-specific transcripts. Our study shows that mRNAs of all three major iGluR subfamilies are expressed in ESCs as well, although their transcription does not result in protein translation or the formation of functional iGluRs.

One possible explanation for this phenomenon might be a microRNA-mediated inhibition of iGluR subunit translation. It is now well known that microRNAs play important roles during development and differentiation (Rosa and Brivanlou, 2009, 2013). Although most of the studies focus on microRNAs that influence and regulate the self-renewal and pluripotency of stem cells (Houbaviy et al., 2003; Gangaraju and Lin, 2009; Wang et al., 2009), one cannot rule out the possibility of microRNAs that target iGluRs in ESCs. It has been shown previously that microRNA-132 plays a critical role during the differentiation of dopaminergic neurons from ESCs (Yang et al., 2012). Interestingly, microRNA-132 also regulates the expression of GluN2A, GluN2B, and GluA1 through a BDNF-dependent mechanism (Kawashima et al., 2010). Thus, it will be an interesting question for future studies if microRNA-132 or other microRNAs are also involved in the translational regulation of iGluRs in stem cells and if those miRNAs are expressed in 46C ESCs as well.

\section{ACKNOWLEDGMENTS}

This work was supported by the International Graduate School of Neuroscience (IGSN), Ruhr University Bochum (Svenja Pachernegg, Elke Muth-Köhne, Steffen Pahl, Michael Karus, and Zhan-Lu Ma-Högemeier), the Ruhr University Research School, Ruhr University Bochum (Svenja Pachernegg, Elke Muth-Köhne, Steffen Pahl, Jan Terhag, and Michael Karus), and the DFG Graduate School 736 "Development and Plasticity of the Nervous System: Molecular, synaptic, and cellular mechanisms," Ruhr University Bochum (Illah Joshi, Jan Terhag). We thank Dr. Austin Smith (Cambridge, UK) for kindly providing the mouse embryonic stem cell line 46C.

\section{REFERENCES}

Aubert, J., Stavridis, M. P., Tweedie, S., O'reilly, M., Vierlinger, K., Li, M., et al. (2003). Screening for mammalian neural genes via fluorescenceactivated cell sorter purification of neural precursors from Soxl-gfp knockin mice. Proc. Natl. Acad. Sci. U.S.A. 100(Suppl. 1), 11836-11841. doi: 10.1073/pnas. 1734197100

Bahn, S., Volk, B., and Wisden, W. (1994). Kainate receptor gene expression in the developing rat brain. J. Neurosci. 14, 5525-5547.

Bain, G., Kitchens, D., Yao, M., Huettner, J. E., and Gottlieb, D. I. (1995). Embryonic stem cells express neuronal properties in vitro. Dev. Biol. 168, 342-357. doi: 10.1006/dbio.1995.1085

Bogen, I. L., Jensen, V., Hvalby, O., and Walaas, S. I. (2009). Synapsindependent development of glutamatergic synaptic vesicles and presynaptic plasticity in postnatal mouse brain. Neuroscience 158, 231-241. doi: 10.1016/j.neuroscience.2008.05.055

Brazel, C. Y., Nunez, J. L., Yang, Z., and Levison, S. W. (2005). Glutamate enhances survival and proliferation of neural progenitors derived from the subventricular zone. Neuroscience 131, 55-65. doi: 10.1016/j.neuroscience.2004. 10.038

Cameron, H. A., McEwen, B. S., and Gould, E. (1995). Regulation of adult neurogenesis by excitatory input and NMDA receptor activation in the dentate gyrus. J. Neurosci. 15, 4687-4692.

Conti, L., Pollard, S. M., Gorba, T., Reitano, E., Toselli, M., Biella, G., et al. (2005). Niche-independent symmetrical self-renewal of a mammalian tissue stem cell. PLoS Biol. 3:e283. doi: 10.1371/journal.pbio.0030283

Contractor, A., Sailer, A. W., Darstein, M., Maron, C., Xu, J., Swanson, G. T., et al. (2003). Loss of kainate receptor-mediated heterosynaptic facilitation of mossyfiber synapses in KA2-/- mice. J. Neurosci. 23, 422-429.

Deisseroth, K., Singla, S., Toda, H., Monje, M., Palmer, T. D., and Malenka, R. C. (2004). Excitation-neurogenesis coupling in adult neural stem/progenitor cells. Neuron 42, 535-552. doi: 10.1016/S0896-6273(04)00266-1

Efroni, S., Duttagupta, R., Cheng, J., Dehghani, H., Hoeppner, D. J., Dash, C., et al. (2008). Global transcription in pluripotent embryonic stem cells. Cell Stem. Cell 2, 437-447. doi: 10.1016/j.stem.2008.03.021

Finley, M. F., Kulkarni, N., and Huettner, J. E. (1996). Synapse formation and establishment of neuronal polarity by P19 embryonic carcinoma cells and embryonic stem cells. J. Neurosci. 16, 1056-1065.

Gangaraju, V. K., and Lin, H. (2009). MicroRNAs: key regulators of stem cells. Nat. Rev. Mol. Cell Biol. 10, 116-125. doi: 10.1038/nrm2621

Golan-Mashiach, M., Dazard, J. E., Gerecht-Nir, S., Amariglio, N., Fisher, T., Jacob-Hirsch, J., et al. (2005). Design principle of gene expression used by 
human stem cells: implication for pluripotency. FASEB J. 19, 147-149. doi: 10.1096/fj.04-2417fje

Haydar, T. F., Wang, F., Schwartz, M. L., and Rakic, P. (2000). Differential modulation of proliferation in the neocortical ventricular and subventricular zones. J. Neurosci. 20, 5764-5774.

Hollmann, M., and Heinemann, S. (1994). Cloned glutamate receptors. Annu. Rev. Neurosci. 17, 31-108. doi: 10.1146/annurev.ne.17.030194.000335

Houbaviy, H. B., Murray, M. F., and Sharp, P. A. (2003). Embryonic stem cellspecific MicroRNAs. Dev. Cell 5, 351-358. doi: 10.1016/S1534-5807(03)00227-2

Jansson, L. C., Wigren, H. K., Nordstrom, T., and Akerman, K. E. (2011). Functional alpha-amino-3-hydroxy-5-methylisoxazole-4-propionic acid receptors in differentiating embryonic neural progenitor cells. Neuroreport 22, 282-287. doi: 10.1097/WNR.0b013e3283457b34

Kawashima, H., Numakawa, T., Kumamaru, E., Adachi, N., Mizuno, H., Ninomiya, M., et al. (2010). Glucocorticoid attenuates brain-derived neurotrophic factor-dependent upregulation of glutamate receptors via the suppression of microRNA-132 expression. Neuroscience 165, 1301-1311. doi: 10.1016/j.neuroscience.2009.11.057

Kim, M., Habiba, A., Doherty, J. M., Mills, J. C., Mercer, R. W., and Huettner, J. E. (2009). Regulation of mouse embryonic stem cell neural differentiation by retinoic acid. Dev. Biol. 328, 456-471. doi: 10.1016/j.ydbio.2009.02.001

Korber, C., Werner, M., Kott, S., Ma, Z. L., and Hollmann, M. (2007). The transmembrane AMPA receptor regulatory protein gamma 4 is a more effective modulator of AMPA receptor function than stargazin (gamma 2). J. Neurosci. 27, 8442-8447. doi: 10.1523/JNEUROSCI.0424-07.2007

Lerma, J. (2003). Roles and rules of kainate receptors in synaptic transmission. Nat. Rev. Neurosci. 4, 481-495. doi: 10.1038/nrn1118

Lilliu, V., Perrone-Capano, C., Pernas-Alonso, R., Diaz Trelles, R., Luca Colucci D'Amato, G., Zuddas, A., et al. (2002). Ontogeny of kainate receptor gene expression in the developing rat midbrain and striatum. Brain Res. Mol. Brain Res. 104, 1-10. doi: 10.1016/S0169-328X(02)00196-1

Liu, X. B., Murray, K. D., and Jones, E. G. (2004). Switching of NMDA receptor 2A and $2 \mathrm{~B}$ subunits at thalamic and cortical synapses during early postnatal development. J. Neurosci. 24, 8885-8895. doi: 10.1523/JNEUROSCI.2476-04.2004

Loturco, J. J., Owens, D. F., Heath, M. J., Davis, M. B., and Kriegstein, A. R. (1995). GABA and glutamate depolarize cortical progenitor cells and inhibit DNA synthesis. Neuron 15, 1287-1298. doi: 10.1016/0896-6273(95)90008-X

Luk, K. C., and Sadikot, A. F. (2004). Glutamate and regulation of proliferation in the developing mammalian telencephalon. Dev. Neurosci. 26, 218-228. doi: $10.1159 / 000082139$

Manent, J. B., Demarque, M., Jorquera, I., Pellegrino, C., Ben-Ari, Y., Aniksztejn, L., et al. (2005). A noncanonical release of GABA and glutamate modulates neuronal migration. J. Neurosci. 25, 4755-4765. doi: 10.1523/JNEUROSCI.055305.2005

Maric, D., Liu, Q. Y., Grant, G. M., Andreadis, J. D., Hu, Q., Chang, Y. H., et al. (2000). Functional ionotropic glutamate receptors emerge during terminal cell division and early neuronal differentiation of rat neuroepithelial cells. J. Neurosci. Res. 61, 652-662. doi: 10.1002/10974547(20000915)61:6<652::AID-JNR9>3.3.CO;2-A

Melloni, R. H. Jr., and Degennaro, L. J. (1994). Temporal onset of synapsin I gene expression coincides with neuronal differentiation during the development of the nervous system. J. Comp. Neurol. 342, 449-462. doi: 10.1002/cne.903420311

Meshorer, E., and Misteli, T. (2006). Chromatin in pluripotent embryonic stem cells and differentiation. Nat. Rev. Mol. Cell Biol. 7, 540-546. doi: 10.1038/nrm1938

Monyer, H., Burnashev, N., Laurie, D. J., Sakmann, B., and Seeburg, P. H. (1994). Developmental and regional expression in the rat brain and functional properties of four NMDA receptors. Neuron 12, 529-540. doi: 10.1016/08966273(94)90210-0

Monyer, H., Seeburg, P. H., and Wisden, W. (1991). Glutamate-operated channels: developmentally early and mature forms arise by alternative splicing. Neuron 6 , 799-810. doi: 10.1016/0896-6273(91)90176-Z

Mulle, C., Sailer, A., Perez-Otano, I., Dickinson-Anson, H., Castillo, P. E., Bureau, I., et al. (1998). Altered synaptic physiology and reduced susceptibility to kainate-induced seizures in GluR6-deficient mice. Nature 392, 601-605. doi: $10.1038 / 33408$
Muth-Kohne, E., Pachernegg, S., Karus, M., Faissner, A., and Hollmann, M. (2010a). Expression of NMDA receptors and Ca2+-impermeable AMPA receptors requires neuronal differentiation and allows discrimination between two different types of neural stem cells. Cell. Physiol. Biochem. 26, 935-946. doi: $10.1159 / 000324002$

Muth-Kohne, E., Terhag, J., Pahl, S., Werner, M., Joshi, I., and Hollmann, M. (2010b). Functional excitatory GABAA receptors precede ionotropic glutamate receptors in radial glia-like neural stem cells. Mol. Cell. Neurosci. 43, 209-221. doi: 10.1016/j.mcn.2009.11.002

Pfaffl, M. W. (2001). A new mathematical model for relative quantification in realtime RT-PCR. Nucleic Acids Res. 29, e45. doi: 10.1093/nar/29.9.e45

Ritter, L. M., Vazquez, D. M., and Meador-Woodruff, J. H. (2002). Ontogeny of ionotropic glutamate receptor subunit expression in the rat hippocampus. Brain Res. Dev. Brain Res. 139, 227-236. doi: 10.1016/S0165-3806(02)00572-2

Rosa, A., and Brivanlou, A. H. (2009). microRNAs in early vertebrate development. Cell Cycle 8, 3513-3520. doi: 10.4161/cc.8.21.9847

Rosa, A., and Brivanlou, A. H. (2013). Regulatory non-coding RNAs in pluripotent stem cells. Int. J. Mol. Sci. 14, 14346-14373. doi: 10.3390/ijms140714346

Scherer, S. E., and Gallo, V. (1998). Expression and regulation of kainate and AMPA receptors in the rat neural tube. J. Neurosci. Res. 52, 356-368. doi: 10.1002/(SICI) 1097-4547(19980501)52:3<356::AID-JNR12>3.3.CO;2-I

Schlett, K. (2006). Glutamate as a modulator of embryonic and adult neurogenesis. Curr. Top. Med. Chem. 6, 949-960. doi: 10.2174/156802606777323665

Sperger, J. M., Chen, X., Draper, J. S., Antosiewicz, J. E., Chon, C. H., Jones, S. B., et al. (2003). Gene expression patterns in human embryonic stem cells and human pluripotent germ cell tumors. Proc. Natl. Acad. Sci. U.S.A. 100, 13350-13355. doi: 10.1073/pnas.2235735100

Vasileva, M., Horstmann, H., Geumann, C., Gitler, D., and Kuner, T. (2012). Synapsin-dependent reserve pool of synaptic vesicles supports replenishment of the readily releasable pool under intense synaptic transmission. Eur. J. Neurosci. 36, 3005-3020. doi: 10.1111/j.1460-9568.2012.08225.x

Wang, Y., Keys, D. N., Au-Young, J. K., and Chen, C. (2009). MicroRNAs in embryonic stem cells. J. Cell. Physiol. 218, 251-255. doi: 10.1002/jcp.21607

Yang, D., Li, T., Wang, Y., Tang, Y., Cui, H., Zhang, X., et al. (2012). miR-132 regulates the differentiation of dopamine neurons by directly targeting Nurr1 expression. J. Cell. Sci. 125, 1673-1682. doi: 10.1242/jcs.086421

Ying, Q. L., and Smith, A. G. (2003). Defined conditions for neural commitment and differentiation. Meth. Enzymol. 365, 327-341. doi: 10.1016/S00766879(03)65023-8

Ying, Q. L., Stavridis, M., Griffiths, D., Li, M., and Smith, A. (2003). Conversion of embryonic stem cells into neuroectodermal precursors in adherent monoculture. Nat. Biotechnol. 21, 183-186. doi: 10.1038/nbt780

Zurmohle, U. M., Herms, J., Schlingensiepen, R., Schlingensiepen, K. H., and Brysch, W. (1994). Changes of synapsin I messenger RNA expression during rat brain development. Exp. Brain Res. 99, 17-24. doi: 10.1007/BF00241408

Conflict of Interest Statement: The authors declare that the research was conducted in the absence of any commercial or financial relationships that could be construed as a potential conflict of interest.

Received: 28 July 2013; accepted: 13 November 2013; published online: 03 December 2013.

Citation: Pachernegg S, Joshi I, Muth-Köhne E, Pahl S, Münster Y, Terhag J, Karus $M$, Werner M, Ma-Högemeier Z-L, Körber C, Grunwald T, Faissner A, Wiese $S$ and Hollmann M (2013) Undifferentiated embryonic stem cells express ionotropic glutamate receptor mRNAs. Front. Cell. Neurosci. 7:241. doi: 10.3389/fncel.2013.00241 This article was submitted to the journal Frontiers in Cellular Neuroscience. Copyright (C) 2013 Pachernegg, Joshi, Muth-Köhne, Pahl, Münster, Terhag, Karus, Werner, Ma-Högemeier, Körber, Grunwald, Faissner, Wiese and Hollmann. This is an open-access article distributed under the terms of the Creative Commons Attribution License (CC BY). The use, distribution or reproduction in other forums is permitted, provided the original author(s) or licensor are credited and that the original publication in this journal is cited, in accordance with accepted academic practice. No use, distribution or reproduction is permitted which does not comply with these terms. 